\title{
Boundaries of College Divisions
}

Council agreed at its meeting on 3 February 1999 that the boundaries of some College Divisions in England should change to match the new NHS regions to be introduced in April 1999. The boundaries of the South Thames, North Thames, Anglia and Oxford and South and West Divisions will change. Four new Divisions will be created which will be the London, the South-East, the Eastern and the South-West. Each member of the Divisions affected by these changes will be contacted by the College's
Registration Office. Elections for the new Divisions will take place over the summer and all results should be known by September 1999. For further information please contact the Secretary (extension 130).

Vanessa Cameron, The Secretary, Royal College of Psychiatrists, 17 Belgrave Square, London SW1X 8PG

\section{Council Report CR68 Behavioural and Cognitive Treatments}

These guidelines were first published by the Royal College of Psychiatrists

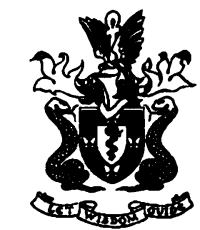
in 1989 following public concern about the use of behavioural methods in certain institutional settings. The forthcoming revised version includes the previous recommendations and is updated to take account of new approaches and techniques developed since 1989. Amongst the issues considered are consent of the patient to treatment, and the use of behavioural and cognitive treatments with children and those with chronic mental illness, learning difficulties and dementia.

CR68, Early 1999, £5.00

Available from Book Sales, Royal College of Psychiatrists

17 Belgrave Square, London SW1X 8PG

Tel +44 (0) 1712352351 (extension 146) $9.30 \mathrm{am}-2$ pm, Fax +44 (0) 1712451231

http://www.rcpsych.ac.uk 